Revista de

Contabilidade e

Organizações

www.rco.usp.br
DOI: http://dx.doi.org/10.11606/rco.v10i27.109014
Journal of

Accounting and

Organizations

\title{
Percepção de justiça organizacional dos gestores no uso do balanced scorecard para a mensuração do desempenho estratégico
}

Ilse Maria Beuren ${ }^{\mathrm{a}}$; Cláudio Marcelo Edwards Barros ${ }^{\mathrm{b}}$; Delci Grapégia Dal Vesco ${ }^{\mathrm{c}}$

a Universidade Federal de Santa Catarina

${ }^{b}$ Universidade Federal do Paraná

${ }^{c}$ Universidade Estadual do Oeste do Paraná

\section{Informações do Artigo}

Histórico do Artigo

Recebido: 28 de dezembro de 2015

Aceito: 17 de agosto de 2016

Palavras chave:

Justiça Distributiva.

Justiça Processual.

Balanced Scorecard.

Desempenho estratégico.

\section{INTRODUÇÃO}

Estudos relativos ao uso de sistemas de mensuração de desempenho estratégico (Strategic Performance Measurement System - SPMS) realçam a tendência das empresas de moldar sistemas de informação conciliando métricas financeiras e não financeiras, ao invés de exclusivamente financeiras (BURNEY; HENLE; WIDENER, 2009). A intenção de comunicar e traduzir indicadores sobre o desempenho subjacente aos empregados é coerente com a busca da empresa em associar objetivos estratégicos e comportamentos individuais (ITTNER; LARCKER; RANDALL, 2003). Nesta direção, Otley (1999) argumenta que a implantação dos sistemas de mensuração de desempenho estratégico se fundamenta na capacidade dessas estruturas de prover alicerces ao alcance de objetivos organizacionais.

Schiemann e Lingle (1997) e Otley (1999) argumentam que a continuidade das organizações no longo prazo está relacionada às atitudes individuais de seus gestores no desempenho de suas atividades. Por outro lado, o conteúdo informacional presente em sistemas de mensuração de desempenho estratégico pode exercer influência sobre atitudes individuais. Diante desta possível relação de influência reversa entre atitudes individuais e sistemas de mensuração de desempenho estratégico, Sprinkle (2003) aduz que as organizações usam esses sistemas não somente para sustentar a tomada de decisões empresariais, mas também para influenciar o comportamento de seus funcionários.

Além da influência sobre a atitude de funcionários, Kaplan e Norton (1996) destacam a capacidade de sistemas de medição de desempenho oferecer sustentação para o modelo estratégico da corporação. Segundo os autores, esses sistemas são capazes de mostrar a interação entre as métricas de desempenho e ações oportunas para a realização de objetivos propostos. Epstein e Manzoni (1997) mencionam que o Balanced Scorecard, visto como um sistema de mensuração de desempenho estratégico, é um recurso capaz de auxiliar na propagação do alinhamento funcional necessário para a materialização da estratégia corporativa.

Autor Correspondente: Tel (48) 3721- 6608

E-mail: ilse.beuren@gmail.com (I. M. Bueren); claudiomedwards@hotmail.com (C. M. E. Barros); delcigrape@gmail.com (D. G. Dal Vesco)

Universidade Federal de Santa Catarina, Campus Reitor João David Ferreira Lima, Trindade, CEP: 88040-970 - Florianópolis, SC - Brasil \section{(1)}


Tomando como base o desenho e os atributos de sistemas de mensuração de desempenho estratégico, dentre eles o BSC, presume-se que podem ser múltiplas as percepções advindas de gestores sobre a associação entre esses sistemas e a busca exitosa dos objetivos corporativos. A percepção resultante do uso desses sistemas é consistente com a proposição de que seu desenho e atributos podem trazer consequências benéficas ou até mesmo maléficas, dado o alcance desses elementos sobre ações individuais (FREEMAN, 2010). E, por consequência, tais percepções mostram o potencial de influenciar empregados a se posicionar sobre o que pode ser considerado justo ou injusto, tendo em vista as iniciativas desencadeadas a partir do conteúdo informacional produzido por esses sistemas.

Assmar, Ferreira e Souto (2005) expõem que o contexto organizacional é um campo proveitoso para aplicações de conhecimentos da psicologia social da justiça. Segundo os autores, percepções e reações sobre justiça (ou injustiça) no ambiente organizacional foram encampadas na temática da justiça organizacional. Assim, estudos que examinam a relação entre sistemas de mensuração de desempenho estratégico e alinhamento organizacional podem ser ancorados em estruturas conceituais presentes na justiça organizacional, mais especificamente, na Justiça Distributiva, Justiça Processual e Justiça Interacional.

Justiça distributiva refere-se à fidedignidade e adequação percebida por funcionários sobre o compartilhamento de resultados alcançados, tais como, reconhecimentos, bonificações e promoções. Já a Justiça Processual captura a densidade de adequação dos processos usados para a tomada de decisões (BURNEY; HENLE; WIDENER, 2009). Por sua vez, a Justiça Interacional realça práticas organizacionais ligadas à relação interpessoal e comunicação da gestão com funcionários (COHEN-CHARASH; SPECTOR, 2001). Esses fundamentos, juntos ou separadamente, podem capturar regularidades entre sistemas de medição de desempenho, como um instrumento de alinhamento estratégico, e a percepção de seu uso para a determinação de comportamentos individuais.

Consistente com proposições e estudos anteriores, o exame empírico realizado por Burney, Henle e Widener (2009) evidencia a percepção de funcionários de uma grande empresa europeia de serviços bancários sobre a influência da justiça organizacional no desempenho funcional dos indivíduos. Nesse estudo, o campo de observação não realizou recortes amostrais dos respondentes, não sendo possível fazer inferências sobre possíveis diferenças de percepção entre indivíduos que ocupam posição de gestão, sendo esta a motivação do presente estudo.

Com base na contextualização apresentada, formulou-se a questão orientadora desta pesquisa: Qual a percepção de justiça distributiva e justiça processual dos gestores no uso do Balanced Scorecard para a mensuração do desempenho estratégico da empresa? Assim, o estudo objetiva averiguar a percepção de justiça organizacional dos gestores no uso do Balanced Scorecard para a mensuração do desempenho estratégico da empresa.

A relevância deste estudo decorre do fato de a modelagem de sistemas de informação utilizada para a avaliação do desempenho estratégico exercer influência no comportamento individual de funcionários e que tais comportamentos, materializados em ações e decisões, podem se refletir no desempenho da empresa ao longo do tempo (CUGUERÓ-ESCOFET; ROSANAS, 2013). Este estudo é importante porque identifica e examina fatores explicativos da relação entre sistemas de medição de desempenho estratégico e a percepção de gestores sobre desempenho estratégico da empresa.

Levando em conta que a percepção de gestores sobre o uso de sistemas de medição de desempenho estratégico representa uma área temática de recorrente interesse de pesquisadores e profissionais de áreas afins (FACHINELLI; GIACOMELLO, 2009; REZENDE; NOGUEIRA, 2012; BEUREN; SANTOS, 2013), o presente estudo visa preencher uma lacuna indicada no estudo de Burney, Henle e Widener (2009), pois busca capturar a percepção sobre justiça organizacional de gestores. Tendo em vista que o presente estudo não se destina a examinar a percepção de empregados sobre o comportamento de gestores em relação a questões como formação de vínculos sociais e afetuosidade, a investigação não fez uso de variáveis de pesquisa que remetem à utilização de constructos fundamentados na Justiça Interacional.

Esse estudo busca evidenciar um fragmento da vivência de gestores de uma empresa industrial quanto ao uso do Balanced Scorecard como sistema de mensuração de desempenho estratégico. Trata-se de uma companhia que iniciou o uso do BSC no ano de 2005, em todas as suas unidades e implementado simultaneamente. O período coincide com a realização de investimentos vultosos em tecnologia da informação, tanto em infraestrutura computacional quanto em especialização de gestores. Os resultados apresentados neste estudo refletem o aprendizado da companhia em utilizar o BSC de forma contundente e compartilhada entre a alta administração e demais funcionários. Adicionalmente, no que diz respeito ao uso do BSC como instrumental de influência sobre comportamentos e atitudes de gestores na propagação de regras justas e alinhadas a princípios ligados à ética, os resultados apresentados podem ser considerados vistosos. 


\section{REVISÃO BIBLIOGRÁFICA}

\subsection{Percepção de justiça organizacional no uso do Balanced Scorecard}

Pode-se descrever a justiça organizacional como a percepção de indivíduos de um grupo sobre como ocorrem trocas no meio organizacional, sejam trocas econômicas ou sociais, ou aquelas que envolvem superiores, subordinados, pares e a organização em si (BEUGRÉ, 1998). Assmar, Ferreira e Souto (2005) sintetizam que a justiça organizacional é a psicologia da justiça aplicada genericamente em ambientes organizacionais. A justiça organizacional desdobra-se em justiça distributiva, justiça processual e justiça interacional (SOTOMAYOR, 2007).

Alicerçada na Teoria da Equidade (ADAMS, 1965), a justiça distributiva busca explicar a reação de indivíduos sobre questões relativas à remuneração, classificações obtidas em avaliações de desempenho, sanções disciplinares, promoções, distribuições de lucros e afins. A Justiça Distributiva tem a capacidade de fundamentar discussões relacionadas à proporcionalidade da justiça (ASSMAR; FERREIRA; SOUTO, 2005). Postula-se que resultados são identificados como justos quando, na percepção de indivíduos do meio, há igualdade de razões entre inversões realizadas e resultados obtidos.

A justiça processual está ligada aos procedimentos e regras estabelecidas para alcançar os objetivos organizacionais, se aqueles são percebidos como justos para os indivíduos (THIBAUT; WALKER, 1975). Segundo Spessatto e Beuren (2013), a justiça processual se refere à ideia de que a preocupação do indivíduo em uma organização não se concentra exclusivamente na justiça traduzida por meio dos resultados, mas relaciona-se com a justiça dos processos existentes para o reconhecimento e a avaliação de desempenho. Portanto, a justiça processual diz respeito à estabilidade formal (ou sua ausência) de processos utilizados para a tomada de decisões e seus reflexos.

Um requisito importante de justiça que envolve os sistemas de controle gerencial, conforme CugueróEscofet e Rosanas (2013), se refere ao modo como as regras do jogo são estabelecidas. Tendo em vista que estes sistemas podem ser utilizados para avaliar e reconhecer desempenhos exitosos ou insatisfatórios. A avaliação do alcance de objetivos e de desempenhos deve assegurar que os processos mediadores sejam consistentes. Segundo Leventhal, Karuza e Fry (1980), isso implica o indivíduo saber antecipadamente os critérios utilizados, por exemplo, para avaliar o desempenho de uma ou de um conjunto de métricas, além do que, estes processos não deveriam trazer contradições.

Com base nestes elementos teóricos é coerente intuir sobre múltiplas associações entre a administração da estratégia organizacional e as justiças distributiva e processual. Essa relação é sustentada pelo fato de pesquisadores utilizarem construtos de justiça distributiva e processual para examinar aspectos de sistemas de controle gerencial (CUGUERÓ-ESCOFET; ROSANAS, 2013). Esses autores propõem que os sistemas de controle gerencial devem ser moldados de modo a distribuir recursos e responsabilidades aos departamentos ou unidades organizacionais para avaliar desempenhos de acordo com o que foi alcançado e a partir de regras explícitas e antecipadamente definidas.

Epstein e Manzoni (1997) e Kaplan e Norton (1997) consideram o BSC como um instrumento de mensuração de desempenho capaz de produzir alinhamento e congruência à estratégia organizacional, e também, de ser capaz de capturar o reflexo de intangíveis de difícil mensuração, dentre eles a capacidade intelectual de indivíduos. No entanto, o exame de disfunções que podem envolver os sistemas de mensuração de desempenho organizacional resulta em uma temática recorrente de pesquisas (CUGUERÓ-ESCOFET; ROSANAS, 2013). Por esta razão e tendo em vista o uso do BSC como instrumento de mensuração de desempenho, pode-se inferir que o desenho de instrumentos de mensuração contém características ligadas à percepção de justiça organizacional, mais especificamente, de comportamentos individuais.

Estudos contemporâneos têm incluído elementos teóricos de justiça organizacional como variáveis mediadoras entre sistemas de controle gerencial e desempenho (BURNEY; HENLE; WIDENER, 2009). CugueróEscofet e Rosanas (2013) propõem que a configuração justa de modelos de controle gerencial deve agregar objetivos de maneira que haja integração entre objetivos individuais e organizacionais. Daí a relevância em se estabelecer a relação com a justiça organizacional, em especial nas vertentes da justiça distributiva e da justiça procedimental. 


\subsection{Balanced Scorecard: um instrumento de medição de desempenho estratégico}

Desenvolvido por Kaplan e Norton (1997), o Balanced Scorecard (BSC) busca explicar a estratégia organizacional por meio do balanceamento de métricas financeiras e não financeiras de desempenho para refletir a estratégia em quatro perspectivas gerais: a) aprendizado e crescimento, relacionada à gestão de pessoas e gestão tecnológica; b) processos internos, focalizada na identificação de processos críticos ao desempenho organizacional; c) clientes, associada à manutenção e captação de clientes; e d) finanças, voltada às mensurações e proposições que descrevam o retorno do capital investido.

Para Kaplan e Norton (1997), o modelo típico da contabilidade se restringe à computação de transações isoladas. Deste modo, é incapaz de incorporar a avaliação de determinados ativos, como, a influência intelectual de membros de um grupo organizacional. É coerente realçar que não faz parte dos objetivos do BSC a mensuração econômica, por exemplo, da capacidade intelectual dos indivíduos de uma organização. No entanto, ao se reconhecer o BSC como um sistema de medição de desempenho estratégico, observa-se a influência da capacidade intelectual sobre o desempenho organizacional.

Há ainda um componente indireto do Balanced Scorecard, realçado por Ittner, Larcker e Randall (2003), que é a intenção da empresa em comunicar e traduzir indicadores com vistas à relacionar objetivos estratégicos e comportamentos individuais. Da mesma forma, com base na ideia defendida por Schiemann e Lingle (1997) e Otley (1999), os sistemas de medição de desempenho estratégico, como, por exemplo, o BSC, proveem informações para alinhar atitudes e objetivos empresariais que traduzam o êxito organizacional.

Flores, Fachinelli e Giacomello (2009) examinaram a adoção do BSC na avaliação da gestão de unidades de negócios de um banco comercial, no Brasil. Segundo os autores, os resultados obtidos são consistentes com a ideia de que a adoção do BSC é capaz de promover o alinhamento do pensamento estratégico em diversos níveis gerenciais da organização pesquisada. Rezende e Nogueira (2012) observaram menor realce de benefícios trazidos a partir do uso do BSC. Segundo os autores, a percepção de gestores sobre as vantagens do BSC se mostrou inconclusiva, fazendo-os inferir sobre a necessidade de novas incursões empíricas que associem o uso do BSC ao campo gerencial.

Com vistas em examinar a proposição de que a criação do BSC se justifica pela deficiência de recursos tradicionais de avaliação de desempenho estratégico, Beuren e Santos (2013) investigaram os fins do BSC para gestores de diversas empresas. Para analisar a percepção dos gestores, utilizaram o instrumento de pesquisa proposto por Wiersma (2009), em que gestores se posicionaram sobre três funções básicas do BSC. Beuren e Santos (2013) confirmaram a proposição da utilidade do BSC e seus fins podem ser ranqueados em: a) planejamento do trabalho; b) relações estratégicas com clientes; e c) coordenação de trabalhos intragrupo.

\section{PROCEDIMENTOS METODOLÓGICOS}

Este estudo, com característica descritiva e abordagem quantitativa, expõe a percepção dos gestores de uma empresa industrial brasileira sobre construtos fundamentados na estrutura teórica da justiça organizacional. Tratase de uma empresa do setor de energia, fundada nos anos de 1950 e pertencente ao mesmo grupo empresarial desde então. A empresa opera com matriz e filiais em cinco estados brasileiros e até o período de levantamento dos dados era responsável por aproximadamente 650 postos de trabalho. A survey, que instrumentaliza o levantamento de percepções dos gestores, foi aplicada em uma empresa industrial brasileira que possui em seu quadro funcional 60 gestores, distribuídos entre analistas seniors, chefes de divisão, gerentes de departamentos e gerentes corporativos. A coleta dos dados resultou em 47 questionários válidos, perfazendo um retorno de 78,33\%, os quais foram respondidos durante o mês de agosto 2014 .

\subsection{Hipóteses}

Para Burney, Henle e Widener (2009), os Sistemas de Medição de Desempenho Estratégico (SMDE) são utilizados nos processos de tomada de decisão. Estes sistemas estarão ligados à estratégia da empresa se forem capazes de: a) influenciar gestores e demais indivíduos a empenhar-se para alcançar desempenho superior; 
b) gerar o sentimento de valorização do indivíduo perante a organização; c) conter as exigências devidas para o funcionamento estável dos processos. Assim, esses autores formularam as seguintes hipóteses testáveis de pesquisa:

H1a: A extensão na qual os empregados percebem que o SMDE reflete o modelo estratégico da corporação está positivamente associada a justiça processual.

H1b: O nível de utilização dos SMDE está positivamente associado com a percepção de justiça processual.

A justiça distributiva tem suas raízes na Teoria da Equidade (BURNEY; HENLE; WIDENER, 2009). Segundo essa Teoria, empregados são capazes de determinar os esforços empreendidos nas atividades que desenvolvem e as recompensas associadas ao desempenho realizado. De acordo com Burney, Henle e Widener (2009), os SDME capazes de traduzir a estratégia e tecnicamente válidos irão facilitar para o empregado a comparação entre benefícios e custos. Diante disso, os autores formularam as seguintes hipóteses de pesquisa:

H2a: Há relação positiva entre o nível de utilização dos SMDE e a percepção de justiça distributiva.

H2b: O nível de utilização dos SMDE é positivamente relacionado à percepção de justiça distributiva.

Apoiando-se em pesquisas prévias que sugerem associação entre justiça distributiva e justiça processual, Burney, Henle e Widener (2009) defendem que, à medida que funcionários acreditam receber compensações justas pelo trabalho realizado, também creem que os processos são justos. Assim, os autores formularam a seguinte hipótese:

H3: A justiça distributiva está associada positivamente com a justiça processual.

Burney, Henle e Widener (2009) argumentam que o comportamento de cidadania organizacional tende a aumentar a performance dos empregados. Podsakoff e MacKenzie (1997) expõem as razões para acreditar que a cidadania melhora o desempenho: a) melhora a coordenação de atividades entre membros de um grupo; b) auxilia no processo de adaptação dos empregados a situações de mudança no ambiente de trabalho; e c) o comportamento de cidadania organizacional exerce influência sobre a produtividade do trabalhador.

Para Burney, Henle e Widener (2009), a literatura sustenta a ideia de que a justiça processual influencia a cidadania organizacional e que, por sua vez, influencia o desempenho. Desse modo, formularam a seguinte hipótese:

H4: A justiça processual está positivamente relacionada com o desempenho do gestor por meio do comportamento de cidadania organizacional.

As hipóteses de pesquisa estabelecidas nos estudos de Burney, Henle e Widener (2009) compõem o modelo teórico-estrutural da presente pesquisa de acordo com a configuração apresentada na Figura 1.

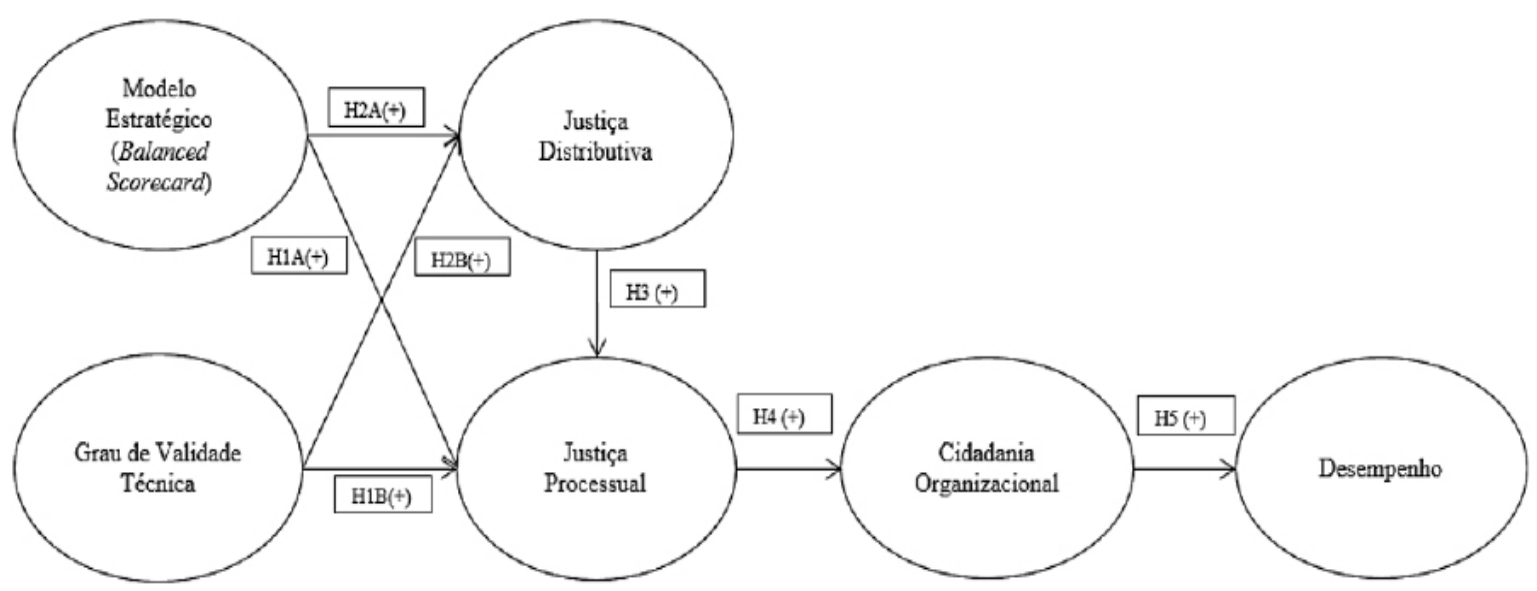

Figura 1. Modelo teórico-estrutural

Fonte: Adaptado de Burney, Henle e Widener (2009).

Nesta pesquisa, os sistemas de mensuração de desempenho estratégico (Strategic Performance Measurement System - SPMS) compreendem o Balanced Scorecard (BSC) utilizado para a mensuração do desempenho estratégico da empresa objeto de estudo. 


\subsection{Instrumento da pesquisa}

O questionário utilizado na survey baseou-se no instrumento de pesquisa desenvolvido no estudo de Burney, Henle e Widener (2009). Inicialmente foram traduzidas as questões. Em seguida, a redação das questões foi adaptada para o instrumento de mensuração de desempenho estratégico utilizado na empresa objeto de estudo, que é o Balanced Scorecard. Tendo em vista a busca pela fidedignidade das questões do instrumento de pesquisa, foram realizadas adaptações de linguagem a partir da análise de quatro pesquisadores com experiência em investigações da área de contabilidade gerencial e contabilidade financeira. As modificações por eles indicadas foram consideradas para aprimoramento, sobretudo de elementos linguísticos que aprimorassem a comunicação das questões que compõe o instrumento de pesquisa.

Em seguida, o questionário, contendo 44 questões em escala Likert foi disponibilizado ao Departamento de Gestão de Pessoas da empresa para ser disponibilizado aos gestores. Na mesma direção da investigação de Burney, Henle e Widener (2006), a validação técnica da survey ocorreu por meio da captação das percepções em escala Likert de sete pontos. O questionário foi disponibilizado eletronicamente por meio do Goolge docs no período de três semanas. No Quadro 1, apresentam-se os construtos que formam o instrumento, bem como a indicação da quantidade de questões.

\begin{tabular}{llc}
\hline \multicolumn{1}{c}{ Construtos } & \multicolumn{1}{c}{ Dimensões das variáveis } & $\begin{array}{c}\text { Número de } \\
\text { questões }\end{array}$ \\
\hline Modelo Estratégico & $\begin{array}{l}\text { Adequação das medidas de desempenho estratégico } \\
\text { Grau de validade técnica }\end{array}$ & $\begin{array}{l}\text { Compreensão e gestão do SMDE } \\
\text { Precisão, acesso e compreensão do SMDE }\end{array}$ \\
Justiça Distributiva & Percepção sobre compensações & 5 \\
Justiça Processual & Processos utilizados para a tomada de decisões & 7 \\
Comportamento de Cidadania & Percepção sobre cidadania organizacional & 7 \\
Organizacional & Comprometimento com o desempenho & 7 \\
Desempenho & & \\
\hline
\end{tabular}

Quadro 1. Construtos da pesquisa

Fonte: Burney, Henle e Widener (2009).

\subsection{Instrumental estatístico}

Na perspectiva da análise descritiva dos dados, inicialmente foram examinados por meio da frequência em percentual de respostas, desde discordo plenamente (1) até concordo plenamente (7), em escala Likert. Essa abordagem permitiu: a) construir a frequência relativa acumulada de respondentes cujo posicionamento fosse de discordância representada pelas ordens 1, 2 e 3 na escala Likert do questionário; b) construir a frequência relativa acumulada de respondentes neutros; e c) construir a frequência relativa acumulada de respondentes com posicionamento de concordância representados pela ordem 5, 6 e 7.

Para o exame multivariado dos construtos de pesquisa foi utilizada a modelagem de equações estruturais. A relação entre os construtos foi estimada para testar as hipóteses de pesquisa conforme o modelo estruturalteórico. Para testar as hipóteses, as inferências estatísticas das relações de causa e efeito ocorreram mediante a comparação entre os sinais obtidos e esperados para as variáveis exógenas e a significância de seus coeficientes angulares. Estes coeficientes foram estimados por meio do método de mínimos quadrados parciais (PLS) utilizando o software estatístico SmartPls versão 2.0. As hipóteses de pesquisa presentes no modelo teórico-estrutural foram examinadas conforme Quadro 2.

\begin{tabular}{llcc}
\hline Variável dependente (endógena) & Variável independente (exógena) & Hipóteses & $\begin{array}{c}\text { Sinais esperados } \\
\text { (relação entre variáveis) }\end{array}$ \\
\hline Justiça Distributiva & Modelo Estratégico Causal & + \\
Justiça Processual & Modelo Estratégico Causal & $\mathrm{H} 1 \mathrm{a}$ & + \\
Justiça Distributiva & Validade técnica & $\mathrm{H} 2 \mathrm{~b}$ & + \\
Justiça Processual & Validade técnica & $\mathrm{H} 1 \mathrm{~b}$ & + \\
Justiça Processual & Justiça Distributiva & $\mathrm{H} 3$ & + \\
Cidadania Organizacional & Justiça Processual & $\mathrm{H} 4$ & + \\
Desempenho & Cidadania Organizacional & $\mathrm{H} 4$ & + \\
\hline
\end{tabular}

Quadro 2. Relações de dependência dos construtos de pesquisa

Fonte: Adaptado de Burney, Henle e Widener (2009). 


\section{DESCRIÇÃO E ANÁLISE DOS RESULTADOS}

\subsection{Estatística descritiva}

Na Tabela 1, apresenta-se um breve perfil dos respondentes do questionário, com vistas a indicar sua possível adequação para responder o instrumento de pesquisa.

Tabela 1. Perfil dos respondentes

\begin{tabular}{llcc}
\hline & & Quantidade & \% \\
\hline \multirow{3}{*}{ Tempo de Empresa } & Até 4 anos & 16 & 34,04 \\
& Entre 4 e 7 anos & 7 & 14,89 \\
& Entre 7 e 10 anos & 9 & 19,15 \\
& Mais de 10 anos & 15 & 31,91 \\
Faixa Etária & Até 20 anos & 0 & 0,0 \\
& Entre 20 e 25 anos & 4 & 8,5 \\
Entre 25 e 30 anos & 13 & 27,7 \\
Nível Hierárquico & Entre 30 e 35 anos & 16 & 34,0 \\
& Mais que 35 anos & 14 & 29,8 \\
Escolaridade & Chefia & 15 & 31,91 \\
& Gerência & 10 & 21,28 \\
& Analistas Seniors & 22 & 46,81 \\
\hline
\end{tabular}

Fonte: Dados da pesquisa.

Observa-se na Tabela 1, que 34,04\% dos respondentes têm pelo menos quatro anos de atuação na empresa e 63,80\% têm no mínimo 30 anos. Sobre o nível hierárquico, mais de 50\% ocupam cargo de liderança e 72,34\% dos respondentes têm especialização acadêmica definida (pós-graduação). Os respondentes do questionário são gestores da empresa, os quais participam do grupo de trabalho que realiza avaliações trimestrais de desempenho estratégico. Na Tabela 2, são apresentadas as frequências relativas sobre as respostas dadas ao construto relacionado ao Modelo Estratégico Causal (MEC). O propósito é evidenciar a percepção dos respondentes sobre a relação entre os objetivos estratégicos da empresa e o conteúdo presente no Balanced Scorecard.

Tabela 2. Modelo Estratégico Causal

\begin{tabular}{|c|c|c|c|}
\hline Questões & Discordantes & Neutros & Concordantes \\
\hline $\begin{array}{l}\text { As informações gerenciais apresentadas no Balanced Scorecard (BSC) } \\
\text { estão alinhadas com o que a empresa busca em sua estratégia de } \\
\text { atuação. }\end{array}$ & $2,13 \%$ & $2,13 \%$ & $95,74 \%$ \\
\hline $\begin{array}{l}\text { As informações gerenciais utilizadas no BSC permitem que o meu } \\
\text { desempenho individual seja avaliado. }\end{array}$ & $4,26 \%$ & $10,64 \%$ & $85,11 \%$ \\
\hline $\begin{array}{l}\text { As informações gerenciais utilizadas no BSC estão relacionadas à } \\
\text { estratégia da empresa. }\end{array}$ & $0,00 \%$ & $6,38 \%$ & $93,62 \%$ \\
\hline $\begin{array}{l}\text { As informações gerenciais contidas no BSC me ajudam a compreender } \\
\text { a estratégia a ser alcançada pela empresa. }\end{array}$ & $0,00 \%$ & $4,26 \%$ & $95,74 \%$ \\
\hline $\begin{array}{l}\text { As informações gerenciais contidas no BSC me ajudam a compreender } \\
\text { as consequências financeiras das minhas decisões e ações. }\end{array}$ & $2,13 \%$ & $10,64 \%$ & $87,23 \%$ \\
\hline $\begin{array}{l}\text { As informações gerenciais contidas no BSC me ajudam a compreender } \\
\text { os possíveis trade-offs presentes entre os indicadores e minhas ações } \\
\text { e decisões. Trade-offs são situações em que dizer "sim" para uma } \\
\text { situação implica em dizer "não" para outra. }\end{array}$ & $4,26 \%$ & $8,51 \%$ & $87,23 \%$ \\
\hline
\end{tabular}

Fonte: Dados da pesquisa 
Tabela 2. Modelo Estratégico Causal (continuação)

\begin{tabular}{|c|c|c|c|}
\hline Questões & Discordantes & Neutros & Concordantes \\
\hline $\begin{array}{l}\text { As informações gerenciais contidas no BSC permitem que eu avalie } \\
\text { a relação de causa e efeito entre minhas ações e os resultados das } \\
\text { medidas do BSC. }\end{array}$ & $6,38 \%$ & $4,26 \%$ & $89,36 \%$ \\
\hline $\begin{array}{l}\text { O modelo de informações gerenciais do BSC recebe forte apoio da } \\
\text { alta administração. }\end{array}$ & $2,13 \%$ & $4,26 \%$ & $93,62 \%$ \\
\hline $\begin{array}{l}\text { As informações gerenciais contidas no BSC demonstram forte relação } \\
\text { com as estratégias de competição da empresa no mercado em que atua. }\end{array}$ & $2,13 \%$ & $0,00 \%$ & $97,87 \%$ \\
\hline $\begin{array}{l}\text { As informações gerenciais contidas no BSC impactam a maneira } \\
\text { como eu desempenho minhas responsabilidades profissionais. }\end{array}$ & $0,00 \%$ & $2,13 \%$ & $97,87 \%$ \\
\hline $\begin{array}{l}\text { As informações gerenciais contidas no BSC são apropriadas para } \\
\text { avaliar meu desempenho individual. }\end{array}$ & $4,26 \%$ & $12,77 \%$ & $82,98 \%$ \\
\hline $\begin{array}{l}\text { As informações contidas no BSC me fornecem informações que } \\
\text { refletem a estratégia da empresa. }\end{array}$ & $0,00 \%$ & $0,00 \%$ & $100,00 \%$ \\
\hline $\begin{array}{l}\text { As informações contidas no BSC me auxiliam a tomar decisões que } \\
\text { criam valor no longo prazo, ao invés de me concentrar apenas em } \\
\text { resultados de curto prazo. }\end{array}$ & $0,00 \%$ & $2,13 \%$ & $97,87 \%$ \\
\hline $\begin{array}{l}\text { As informações contidas no BSC são úteis porque nelas constam } \\
\text { múltiplas medidas de avaliação de desempenho. }\end{array}$ & $4,26 \%$ & $10,64 \%$ & $85,11 \%$ \\
\hline Média & $2,28 \%$ & $5,63 \%$ & $92,10 \%$ \\
\hline
\end{tabular}

Fonte: Dados da pesquisa.

Verifica-se na Tabela 2, que a maior frequência de respostas está nos pontos de concordância da escala Likert, seguido de neutralidade e discordância, com média 92,10\%, 5,63\% e 2,28\%, respectivamente. Sobre a relação entre a atuação da empresa em alcançar objetivos estratégicos e as informações contidas no BSC, adicionado à compreensão da estratégia, 95,74\% dos respondentes são concordantes. Além disso, 97,87\% afirmam que as informações contidas no BSC os auxiliam a tomar decisões que priorizam resultados de longo prazo. Os dados indicam ainda que, por meio do BSC, a administração da companhia consegue comunicar aos seus gestores o modelo estratégico e este pode exercer influência sobre os comportamentos e os resultados individuais. Além disso, 97,87\% dos respondentes concordam que as informações gerenciais presentes no BSC impactam a maneira como desempenham suas atividades.

O Grau de Validade Técnica (VT) do BSC na percepção de seus gestores é examinado na Tabela 3. A finalidade é verificar a capacidade do BSC em envolver gestores e auxiliá-los a manter o controle dos processos aos quais estão ligados (BURNEY; HENLE; WIDENER, 2009).

Tabela 3. Grau de Validade Técnica

\begin{tabular}{lccc}
\hline Questões & Discordantes & Neutros & Concordantes \\
\hline As informações fornecidas pelo BSC são precisas. & $4,26 \%$ & $6,38 \%$ & $89,36 \%$ \\
As informações fornecidas pelo BSC são acessíveis. & $4,26 \%$ & $0,00 \%$ & $95,74 \%$ \\
As informações fornecidas pelo BSC são confiáveis & $4,26 \%$ & $0,00 \%$ & $95,74 \%$ \\
As informações fornecidas pelo BSC são divulgadas a tempo & $6,38 \%$ & $6,38 \%$ & $87,23 \%$ \\
de desencadearem decisões apropriadas. & $2,13 \%$ & $0,00 \%$ & $97,87 \%$ \\
As informações fornecidas pelo BSC são compreensíveis. & $\mathbf{4 , 2 6 \%}$ & $\mathbf{2 , 5 5 \%}$ & $\mathbf{9 3 , 1 9 \%}$ \\
Média & & & \\
\hline
\end{tabular}

Fonte: Dados da pesquisa.

Observa-se na Tabela 3 maior frequência relativa nos pontos de concordância da escala Likert para o construto de validade técnica. Nota-se que a percepção dos respondentes está relacionada ao realce para a compreensibilidade $(97,87 \%)$, confiança $(95,74 \%)$ e acessibilidade $(95,74 \%)$ das informações presentes no BSC. No entanto, aproximadamente $13 \%$ dos respondentes (6,38\% de discordantes e $6,38 \%$ de neutros) percebem que a relação de tempestividade entre o suprimento de informações e o encadeamento de ações direcionadas à solução de questões relacionadas a gestão da estratégia pode ser diminuída. 
Na Tabela 4, são apresentadas as frequências do construto da Justiça Distributiva (JD). Neste aspecto, busca-se descrever a reação dos respondentes sobre questões relativas à justiça percebida em termos de compensações e reconhecimento pelos esforços empreendidos.

Tabela 4. Justiça distributiva

\begin{tabular}{|c|c|c|c|}
\hline Questões & Discordantes & Neutros & Concordantes \\
\hline $\begin{array}{l}\text { Minhas compensações (por exemplo, remuneração, reconhecimento, } \\
\text { promoções) refletem o esforço que coloco nas atividades que desenvolvo. }\end{array}$ & $4,26 \%$ & $4,26 \%$ & $91,49 \%$ \\
\hline $\begin{array}{l}\text { Minhas compensações são apropriadas ao trabalho que tenho } \\
\text { desenvolvido. }\end{array}$ & $6,38 \%$ & $8,51 \%$ & $85,11 \%$ \\
\hline $\begin{array}{l}\text { Minhas compensações refletem a contribuição que tenho dado ao } \\
\text { desempenho da empresa. }\end{array}$ & $6,38 \%$ & $6,38 \%$ & $87,23 \%$ \\
\hline Minhas compensações são justas considerando minha performance. & $4,26 \%$ & $4,26 \%$ & $91,49 \%$ \\
\hline Média & $5,32 \%$ & $5,85 \%$ & $\mathbf{8 8 , 8 3 \%}$ \\
\hline
\end{tabular}

Fonte: Dados da pesquisa.

De acordo com a Tabela 4, a maior frequência de respondentes consta como concordantes. Sobre a percepção de que as compensações são justas e que estas refletem os esforços empreendidos nas atividades, $91,49 \%$ são concordantes. Aproximadamente $15 \%$ mostraram-se discordantes $(6,38 \%)$ e neutros $(8,51 \%)$ sobre a adequação entre compensações e o trabalho realizado. E 13\% dos respondentes não percebem como forte a relação entre a contribuição realizada por eles e a compensação equivalente.

$\mathrm{Na}$ Tabela 5, mostram-se as frequências obtidas para o constructo de Justiça Processual. O intuito é verificar a percepção dos respondentes sobre a justiça presente em regras e procedimentos da organização (THIBAUT; WALKER, 1975).

Tabela 5. Justiça processual

\begin{tabular}{|c|c|c|c|}
\hline Questões & Discordantes & Neutros & Concordantes \\
\hline $\begin{array}{l}\text { Tenho liberdade para expressar meus pontos de vista e percepções durante } \\
\text { o processo de tomada de decisões da empresa. }\end{array}$ & $12,77 \%$ & $4,26 \%$ & $82,98 \%$ \\
\hline $\begin{array}{l}\text { Tenho influência nas compensações obtidas por procedimentos utilizados } \\
\text { na tomada decisões da empresa. }\end{array}$ & $8,51 \%$ & $17,02 \%$ & $74,47 \%$ \\
\hline $\begin{array}{l}\text { Os procedimentos utilizados para tomar decisões na empresa são aplicados } \\
\text { de forma consistente. }\end{array}$ & $6,38 \%$ & $8,51 \%$ & $85,11 \%$ \\
\hline $\begin{array}{l}\text { Os procedimentos utilizados para tomar decisões na empresa são livres de } \\
\text { preconceito. }\end{array}$ & $6,38 \%$ & $8,51 \%$ & $85,11 \%$ \\
\hline $\begin{array}{l}\text { Os procedimentos utilizados para tomar decisões na empresa são baseados } \\
\text { em informações precisas. }\end{array}$ & $4,26 \%$ & $4,26 \%$ & $91,49 \%$ \\
\hline $\begin{array}{l}\text { Eu posso recorrer das compensações obtidas por procedimentos utilizados } \\
\text { na tomada de decisões da empresa. }\end{array}$ & $10,64 \%$ & $6,38 \%$ & $82,98 \%$ \\
\hline $\begin{array}{l}\text { Os procedimentos utilizados para se tomar decisões na empresa seguem } \\
\text { princípios éticos e morais. }\end{array}$ & $4,26 \%$ & $2,13 \%$ & $93,62 \%$ \\
\hline Média & $7,60 \%$ & $7,30 \%$ & $85,11 \%$ \\
\hline
\end{tabular}

Fonte: Dados da pesquisa.

Os respondentes percebem que o processo de tomada de decisão na empresa ocorre mediante uso de informações precisas $(91,49 \%)$ e que tais decisões seguem princípios éticos e morais $(93,62 \%)$. Embora duas variáveis do construto realcem a presença de justiça nos processos de tomada de decisão da empresa, no que a tange à liberdade em expressar percepções durante os processos de tomada de decisão, 17\% se posicionaram discordantes $(12,77 \%)$ ou neutros $(4,26 \%)$.

O construto relacionado ao comportamento de cidadania organizacional é examinado na Tabela 6. Buscase descrever a percepção dos respondentes sobre comportamentos espontâneos, não formalmente relacionados aos papéis individuais exercidos, mas que podem fomentar o cumprimento de objetivos organizacionais (BURNEY; HENLE; WIDENER, 2009). 
Tabela 6. Cidadania organizacional

\begin{tabular}{|c|c|c|c|}
\hline Questões & Discordantes & Neutros & Concordantes \\
\hline $\begin{array}{l}\text { Desempenho minhas atividades acima do que é estabelecido pelas } \\
\text { normas da empresa. }\end{array}$ & $0,00 \%$ & $4,26 \%$ & $95,74 \%$ \\
\hline $\begin{array}{l}\text { Na empresa, aviso antecipadamente quando não é possível chegar ao } \\
\text { trabalho. }\end{array}$ & $0,00 \%$ & $2,13 \%$ & $97,87 \%$ \\
\hline $\begin{array}{l}\text { Na empresa, realizo intervalos de trabalho (folgas) não regulares } \\
\text { (extras). }\end{array}$ & $40,43 \%$ & $10,64 \%$ & $48,94 \%$ \\
\hline $\begin{array}{l}\text { No trabalho, gasto tempo excessivo com contatos de natureza pessoal } \\
\text { em meios de comunicação disponíveis. }\end{array}$ & $72,34 \%$ & $10,64 \%$ & $17,02 \%$ \\
\hline $\begin{array}{l}\text { Na empresa, às vezes reclamo por coisas que não são relevantes para o } \\
\text { meu trabalho. }\end{array}$ & $72,34 \%$ & $12,77 \%$ & $14,89 \%$ \\
\hline $\begin{array}{l}\text { No desenvolvimento das minhas atividades, conservo e protejo os bens } \\
\text { da empresa. }\end{array}$ & $2,13 \%$ & $0,00 \%$ & $97,87 \%$ \\
\hline $\begin{array}{l}\text { Costumo aderir a regras informais concebidas para manter a ordem no } \\
\text { ambiente de trabalho. }\end{array}$ & $21,28 \%$ & $10,64 \%$ & $68,09 \%$ \\
\hline Média & $29,79 \%$ & $7,30 \%$ & $62,92 \%$ \\
\hline
\end{tabular}

Fonte: Dados da pesquisa.

A Tabela 6 evidencia que mais de 95\% dos respondentes afirmam desenvolver atividades em um nível de envolvimento acima do que consideram mínimo pelas normas da companhia. Mais de $97 \%$ considera que conserva adequadamente os bens da empresa quando desenvolve suas atividades. Mais da metade (51,06\%) afirma que não realiza intervalos irregulares durante o trabalho e não utiliza tempo excessivo com contatos de natureza não profissional (82,98\%). Além disso, aproximadamente $85 \%$ dos respondentes dizem não se envolver em queixas sobre assuntos irrelevantes ao seu ofício.

O construto que examina a percepção dos respondentes sobre o Desempenho (DES) de suas próprias atividades é apresentado na Tabela 7.

Tabela 7. Desempenho

\begin{tabular}{|c|c|c|c|}
\hline Questões & Discordantes & Neutros & Concordantes \\
\hline $\begin{array}{l}\text { Exerço adequadamente as funções que me foram confiadas no meu } \\
\text { trabalho. }\end{array}$ & $0,00 \%$ & $0,00 \%$ & $100,00 \%$ \\
\hline $\begin{array}{l}\text { Cumpro as responsabilidades especificadas na descrição do meu trabalho } \\
\text { (descrição de cargo). }\end{array}$ & $0,00 \%$ & $0,00 \%$ & $100,00 \%$ \\
\hline $\begin{array}{l}\text { Executo as tarefas esperadas por meus pares (colegas da mesma função, } \\
\text { subordinados ou superiores). }\end{array}$ & $0,00 \%$ & $4,26 \%$ & $95,74 \%$ \\
\hline Atendo aos requisitos formais no desempenho da minha função._ & $2,13 \%$ & $0,00 \%$ & $97,87 \%$ \\
\hline $\begin{array}{l}\text { Envolvo-me em atividades que influenciam diretamente a minha avaliação } \\
\text { anual de desempenho. }\end{array}$ & $2,13 \%$ & $2,13 \%$ & $95,74 \%$ \\
\hline $\begin{array}{l}\text { Negligencio (deixo de lado) partes do trabalho que meus pares são } \\
\text { obrigados a desenvolver (colegas da mesma função ou subordinados ou } \\
\text { superiores). }\end{array}$ & $87,23 \%$ & $0,00 \%$ & $12,77 \%$ \\
\hline Às vezes, falho ao desempenhar minhas atividades essenciais. & $53,19 \%$ & $8,51 \%$ & $38,30 \%$ \\
\hline Média & $20,67 \%$ & $2,13 \%$ & $77,20 \%$ \\
\hline
\end{tabular}

Fonte: Dados da pesquisa.

Verifica-se na Tabela 7, sobre o exercício das atividades individuais em concordância com requisitos funcionais das atividades, a totalidade dos respondentes considera que exerce adequadamente o ofício atribuído e que cumpre as responsabilidades designadas. Além de atender os requisitos formais das funções $(97,87 \%)$, os respondentes percebem que atuam visando atender a expectativa dos seus pares $(95,74 \%)$, sem deixar de diligenciar sobre o que é necessário que estes pares devam realizar para concluir um processo ou atividade (87,23\%). Por outro lado, $38,30 \%$ dos respondentes reconhecem falhar no exercício de tarefas essenciais ao cargo que desempenham.

\subsection{Equações estruturais}

Levando em consideração a utilização de construtos já validados em estudos anteriores, serão considerados satisfatórios construtos com alfa de Cronbrach maiores que 0,70 (HAIR JR et al., 2005). Para executar o modelo 
de equações estruturais procedeu-se à avaliação de três formas: validade convergente, validade discriminante e confiabilidade. Os testes estatísticos do modelo são apresentados na Tabela 8.

Tabela 8. Testes estatísticos do modelo

\begin{tabular}{|c|c|c|c|c|c|}
\hline \multicolumn{2}{|c|}{ Construtos } & \multirow{2}{*}{$\begin{array}{c}\text { Coef. R2 } \\
-\end{array}$} & \multirow{2}{*}{$\begin{array}{c}\text { Coef. Conf. } \\
\text { Composta (CC) } \\
0,92\end{array}$} & \multirow{2}{*}{$\begin{array}{c}\text { Coef. Alfa } \\
\text { Cronbach } \\
0,91\end{array}$} & \multirow{2}{*}{$\begin{array}{l}\text { Variância média } \\
\text { extraída (AVE) } \\
0,55\end{array}$} \\
\hline $\mathrm{BSC}$ & & & & & \\
\hline Cidadania_Org. & & 0,09 & 0,72 & 0,42 & 0,46 \\
\hline Desempenho & & 0,43 & 0,87 & 0,83 & 0,59 \\
\hline Justiça & J_Distributiva & 0,38 & 0,94 & 0,92 & 0,81 \\
\hline Organizacional & J_Processual & 0,56 & 0,94 & 0,92 & 0,67 \\
\hline Validade Técnic & & - & 0,86 & 0,81 & 0,56 \\
\hline
\end{tabular}

Fonte: Dados da pesquisa.

Observa-se na Tabela 8, que o coeficiente de confiabilidade composta, utilizado para avaliar se o indicador mensurou adequadamente os construtos, foi validado (superior a 0,70) (FORNELL; LARCKER, 1981). Assim, em consonância com o modelo estrutural (BURNEY; HENLE; WIDENER, 2009), que permite a validade de conteúdo, não foi descartada nenhuma variável latente (VL).

Para a variável latente cidadania organizacional, obteve-se um poder explicativo de 0,42 e 0,46 para o alfa de Cronbach e para a AVE, os quais são considerados baixos. Sem descartar a suposição de que este resultado potencializa a perda de força explicativa do constructo, optou-se por mantê-lo levando em conta que este compõe o modelo teórico-estrutural utilizado. Conforme Tabela 9, a validade convergente foi analisada pelos resultados da variância média extraída maior que 0,50 (FORNELL; LARCKER, 1981).

Tabela 9. Validade Discriminante

\begin{tabular}{lcccccc}
\hline \multicolumn{1}{c}{ Construtos } & BSC & $\begin{array}{c}\text { Cidadania. } \\
\text { Org. }\end{array}$ & Desempenho & J_Distributiva & J_Processual & $\begin{array}{c}\text { Validade } \\
\text { Técnica }\end{array}$ \\
\hline BSC & $\mathbf{0 , 7 4}$ & & & & \\
Cidadania_Org. & 0,59 & $\mathbf{0 , 6 8}$ & & & \\
Desempenho & 0,63 & 0,66 & $\mathbf{0 , 7 7}$ & & \\
J_Distributiva & 0,49 & 0,27 & 0,28 & $\mathbf{0 , 9 0}$ & & \\
J_Processual & 0,59 & 0,30 & 0,30 & 0,69 & $\mathbf{0 , 8 2}$ & $\mathbf{0 , 7 5}$ \\
Validade Técnica & 0,61 & 0,41 & 0,53 & 0,59 & 0,50 & \\
\hline
\end{tabular}

Nota: As raízes quadradas da Variância Média Extraída estão na diagonal

Fonte: Dados da pesquisa.

A validade discriminante pode ser observada na Tabela 9, pelo critério de Fornell e Larcker (1981). Substituindo a VME pela confiabilidade composta, verifica-se o critério de Gaski e Nevin (1985), que indica a validade discriminante do modelo. Portanto, o modelo atende aos dois critérios de validade.

A validação do modelo estrutural consiste na verificação dos valores do R2. A Tabela 8 indica que o desempenho é diretamente explicado em $43 \%$ pela cidadania organizacional. Isso sustenta a ideia de que comportamentos considerados informais e voltados ao cumprimento de objetivos organizacionais exercem forte influência na percepção de gestores em relação ao seu próprio desempenho. Há índicos que corroboram com a ideia de que a cidadania organizacional tende a aumentar o desempenho do gestor (BURNEY; HENLE; WIDENER, 2009). Condizente com Podsakoff, Ahearne e MacKenzie (1997), sugere-se que a cidadania organizacional pode influenciar a coordenação de atividades, melhorando assim a produtividade dos envolvidos.

Outro aspecto observado na terceira etapa centra-se no teste da hipótese, que avaliou a significância de estimativas dos parâmetros. Na Tabela 10 é reportado o resultado dos coeficientes que proveem evidências para o exame das hipóteses de pesquisa para sustentar o modelo teórico apresentado na Figura 1. 
Tabela 10. Modelo Estrutural

\begin{tabular}{llcc}
\hline Hipóteses & & Coeficiente & Sinais obtidos \\
\hline H1a & BSC - J_Processual & $0,34^{* * *}$ & + \\
H1b & Validade Tecnica - J_Processual & $(0,03)$ & - \\
H2a & BSC - J_Distributiva & 0,21 & + \\
H2b & Validade Tecnica - J_Distributiva & $0,46^{* *}$ & + \\
H3 & J_Distributiva - J_Processual & $0,54^{*}$ & + \\
H4 & J_Processual - Cidadania_Org. & $0,30^{* *}$ & + \\
H5 & Cidadania_Org. - Desempenho & $0,66^{*}$ & + \\
\hline
\end{tabular}

Obs.: significante ao nível de $* * * 10 \%, * * 5 \%$ e $* 1 \%$.

Fonte: Dados da pesquisa.

Os resultados obtidos para $\mathrm{H} 1 \mathrm{~b}$ não sustentam a hipótese de que o nível de utilização do BSC, percebido por meio do construto de Grau de Validade Técnica, está positivamente associado com a percepção de justiça processual (H1b), uma vez que não foi estatisticamente significante. Não há evidências para sustentar que a compreensão e acessibilidade dos gestores e a precisão da validade técnica sejam fortes o suficiente para influenciar a percepção de justiça processual. Uma das explicações pode estar ligada a tempestividade presente entre a geração de informações gerenciais e seu efetivo uso para o desencadeamento de ações apropriadas.

Os resultados obtidos para o teste de H2a rejeitam a hipótese de que há relação positiva entre o nível de utilização do BSC e a percepção de justiça distributiva. Portanto, os gestores não percebem que o uso do BSC se reflete em uma melhor equidade na distribuição das compensações (BURNEY; HENLE; WIDENER, 2009). Portanto, não foi possível confirmar que os esforços dos gestores empreendidos nas atividades que desenvolvem refletem as recompensas associadas ao desempenho realizado.

Para as hipóteses restantes, há evidências para sustentá-las ao nível de 1\%, 5\% e 10\% de significância estatística. O modelo estratégico causal, representado pelo Balanced Scorecard, é capaz de influenciar a justiça processual (H1a). Tais evidências sugerem que o BSC exerce influência sobre o processo de tomada de decisão, sendo capaz de influenciar a percepção de gestores sobre formas de compensação por esforços empreendidos, bem como processos e regras utilizadas na tomada de decisões relevantes à estratégia da organização.

Os resultados da hipótese H2b indicam que o grau de validade técnica é positivamente relacionado com a percepção de justiça distributiva, portanto aceita-se H2b. O conceito de grau de validade técnica está ligado à capacidade do BSC em envolver gestores de modo a explicar a sua reação sobre questões relativas à remuneração, promoções, distribuições de lucros e afins.

$\mathrm{Na}$ hipótese $\mathrm{H} 3$, os resultados indicam que a justiça distributiva influencia positivamente a justiça processual, portanto aceita-se H3. Burney, Henle e Widener (2009) defendem que, à medida que funcionários acreditam receber compensações justas pelo trabalho realizado, também percebem que os processos são justos.

Sobre a hipótese relacionada à percepção de que a justiça processual influencia a cidadania organizacional (H4), há evidências para sustentá-la ao nível de significância de 5\%. Também há evidências para afirmar que os comportamentos observados por meio do construto de cidadania organizacional são capazes de influenciar o desempenho dos respondentes no exercício de suas atividades (H4).

\section{CONCLUSÕES}

Este estudo objetivou averiguar a percepção de justiça organizacional dos gestores no uso do Balanced Scorecard para a mensuração do desempenho estratégico da empresa. Com base nos resultados da pesquisa, a primeira conclusão refere-se à relação entre o Modelo Estratégico Causal, Justiça Distributiva e Justiça Processual (hipóteses H2a, H1a e H3). De acordo com a survey realizada, mais de 95\% dos respondentes concordam, em algum nível, que o conteúdo informacional do BSC auxilia na compreensão da estratégia da companhia. Aliado a isso, $89,36 \%$ dos respondentes conseguem perceber relação de causa e efeito entre suas atitudes e os resultados 
mensurados a partir do BSC. Adicionalmente, 97,87\% concordam que as informações gerenciais do BSC impactam a maneira como suas responsabilidades são desempenhadas.

A captura dessas percepções coaduna com Ittner, Larcker e Randall (2003), que a intenção da empresa em comunicar e traduzir indicadores de desempenho subjacente é coerente com sua busca em associar objetivos estratégicos e comportamentos individuais. Em consonância com os resultados apresentados pelo modelo de equações estruturais, a percepção dos gestores é que o modelo estratégico causal exerce influência sobre as variáveis que capturam a justiça percebida em termos de compensação. Mais de $91 \%$ dos respondentes concordam que as compensações obtidas refletem o esforço empreendido e tais compensações são justas considerando o desempenho obtido. Diante disso, os dados sugerem que, à medida que o modelo estratégico se expande em sua capacidade de influenciar o desempenho de responsabilidades individuais, maior pode ser o efeito sobre a percepção de justiça em termos de compensação. A pesquisa sugere também sua influência sobre a percepção da justiça em processos e regras direcionados à tomada de decisões.

A segunda conclusão examina o reflexo do grau de validade técnica sobre a justiça distributiva e justiça processual (hipóteses $\mathrm{H} 2 \mathrm{~b}$ e H1b). O conceito de grau de validade técnica está ligado à capacidade do BSC de dar suporte aos gestores de modo a auxiliá-los a controlar os processos nos quais estão envolvidos. Mais de $90 \%$ dos respondentes reconhecem a eficiência do BSC da empresa e a análise multivariada dos dados sustenta a ideia de que a compreensibilidade, precisão e consistência percebidas no BSC são capazes de exercer influência sobre a justiça relacionada a reconhecimentos, promoções e remuneração. Depreende-se que o grau de validade técnica observado indiretamente, por meio das variáveis que privilegiam a comunicação e a compreensão do BSC, vai além da consistência interna do construto e é capaz de explicar a reação de indivíduos sobre questões relativas à remuneração, promoções, distribuições de lucros e afins.

A terceira conclusão refere-se à influência da justiça presente nos processos e cidadania organizacional percebida pelos respondentes (H4). A percepção da presença de princípios éticos na tomada de decisões é patente com $93,62 \%$ de concordância. Aliado a isso, 91,49\% concordam com o uso e informações precisas na tomada de decisões e $85,11 \%$ afirmam que os processos são aplicados de forma consistente. Isso sugere que os respondentes conhecem o modo pelo qual são estabelecidas as regras, o que, segundo Cugueró-Escofet e Rosanas (2013), compreende importante requisito de justiça envolvendo SCG. Esses percentuais sugerem que os critérios balizadores para a tomada de decisões são conhecidos antecipadamente pelos envolvidos e não indicam presença de contradições, o que converge com a ideia propugnada por Leventhal, Karuza e Fry (1980).

$\mathrm{Na}$ abordagem multivariada dos dados, observou-se influência significativa estatisticamente da percepção de justiça processual sobre a cidadania organizacional, o que pode ser uma relação interessante a considerar a composição da variável latente utilizada como proxy de cidadania organizacional. No que se refere aos comportamentos espontâneos informais, mas considerados úteis para influenciar desempenhos, 68,09\% costumam aderir a regras informais com vistas à manter a ordem no ambiente de trabalho. Além disso, 95,74\% dos respondentes consideram que seu envolvimento está acima do mínimo estabelecido pelas normas da empresa para o desempenho regular de suas responsabilidades.

A quarta conclusão analisa a relação entre cidadania organizacional e desempenho em si. A análise multivariada apresenta dados que sustentam a ideia de que comportamentos considerados informais e voltados ao cumprimento de objetivos organizacionais exercem forte influência sobre a percepção de gestores em relação ao seu próprio desempenho. A considerar que $95,74 \%$ dos respondentes exercem suas responsabilidades visando atender expectativas de seus pares e que $87,23 \%$ não deixam de lado partes do trabalho que seus pares são obrigados a fazer, há índicos que corroboram com a ideia de que a cidadania organizacional tende a aumentar o desempenho do funcionário (BURNEY; HENLE; WIDENER, 2009). Condizente com Podsakoff, Ahearne e MacKenzie (1997), as frequências e a relação multivariada apresentadas sugerem que a cidadania organizacional pode influenciar a coordenação de atividades e melhorar a produtividade dos envolvidos.

Ressalte-se que esta pesquisa não levou em consideração a evolução e modificação das percepções dos usuários do SCG ao longo do tempo, dado que a investigação considerou um recorte temporal único, o que constitui uma limitação de pesquisa. No entanto, os resultados apresentados permitem inferir que o BSC pode ser caracterizado como um artefato instituído na corporação. Como sugestão para estudos futuros, recomenda-se a triangulação dos dados quantitativos com entrevistas abertas junto ao grupo de gestores de diferentes níveis hierárquicos, o que pode prover sustentação para os resultados ora observados.

\section{REFERÊNCIAS}


ADAMS, J.S. Inequity in social exchange. In: Berkowitz, L. (org.). Advances in experimental social psychology. Nova York: Academic Press, 1965. Vol. 2. pp 267-299.

ASSMAR, E.M.L.; FERREIRA, M.C.; SOUTO, S.D.O. Justiça organizacional: uma revisão crítica da literatura. Psicologia: Reflexão e Crítica, v. 18, n. 3, p. 443-453, 2005.

BEUREN, I.M.; SANTOS, A.C.D. Balanced Scorecard: fins de sua utilização por gestores. Revista Economia e Gestão, v. 13, n. 33, p. 108-127, 2013.

BEUGRÉ, C.D. Managing fairness in organizations. Westport, Connecticut: Greenwood Publishing Group, 1998.

BURNEY, L.L.; HENLE, C.A.; WIDENER, S.K. A path model examining the relations among strategic performance measurement system characteristics, organizational justice, and extra-and in-role performance. Accounting, Organizations and Society, v. 34, n. 3, p. 305-321, 2009.

COHEN-CHARASH, Yochi; SPECTOR,PaulE. Therole ofjusticein organizations:Ameta-analysis. Organizational behavior and human decision processes, v. 86, n. 2, p. 278-321, 2001.

CUGUERÓ-ESCOFET, N.; ROSANAS, J.M.. The just design and use of management control systems as requirements for goal congruence. Management Accounting Research, v. 24, n. 1, p. 23-40, 2013.

EPSTEIN, M.J.; MANZONI, J.F. The Balanced Scorecard and Tableau de Bord: a global perspective on translating strategy into action. Fontainebleau: Insead, 1997.

FLORES E.L.; FACHINELLI, A.C.; GIACOMELLO, C.P. O Balanced Scorecard como condutor do processo de alinhamento do pensamento estratégico no Banco Alfa. In: Encontro Anual da Associação Nacional dos Programas de Pós-Graduação em Administração, 33., 2009, São Paulo. Anais... Rio de Janeiro: ANPAD, 2009.

FORNELL, C.; LARCKER, D.F. Evaluating structural equation models with unobservable variables and measurement error. Journal of Marketing Research, v. 18, n. 1, p. 39-50, 1981.

FREEMAN, R.E. Strategic management: a stakeholder approach. Cambridge: Cambridge University Press, 2010.

GASKI, J.F.; NEVIN, J.R. The differential effects of exercised and unexercised power sources in a marketing channel. Journal of Marketing Research, v. 22, n. 2, p. 130-142, 1985.

HAIR JR, J.F.; ANDERSON, R.E.; TATHAM, R.L.; BLACK, W.C. Análise multivariada de dados. Porto Alegre: Bookman, 2005.

ITTNER, C.D.; LARCKER, D.F.; RANDALL, T. Performance implications of strategic performance measurement in financial services firms. Accounting, Organizations and Society, v. 28, n. 7, p. 715-741, 2003.

KAPLAN, R.S.; NORTON, D.P. The balanced scorecard: translating strategy into action. Boston: Harvard Business Press, 1996.

LEVENTHAL, G.S.; KARUZA, J.; FRY, W.R. Beyond fairness: a theory of allocation preferences. In: Mikula, G. (Ed.). Justice and social interaction. Bern: Hans Huber Publishers, 1980. pp 167-218.

OTLEY, D. Performance management: a framework for management control systems research. Management accounting research, v. 10, n. 4, p. 363-382, 1999.

PODSAKOFF, P.M.; AHEARNE, M.; MACKENZIE, S.B. Organizational citizenship behavior and the quantity and quality of work group performance. Journal of Applied Psychology, v. 82, n. 2, p. 262-270, 1997.

PODSAKOFF, P.M.; MACKENZIE, S.B. Impact of organizational citizenship behavior on organizational performance: A review and suggestion for future research. Human Performance, v. 10, n. 2, p. 133-151, 1997.

REZENDE, J.F.; NOGUEIRA, A.R. Alinhamento estratégico e balanceamento da performance: um estudo a partir da percepção de gerentes de agências bancárias. Revista ADM. MADE, v. 16, n. 3, p. 37-59, 2012.

SCHIEMANN, W.A.; LINGLE, J.H. Seven greatest myths of measurement. Management Review-Saranac Lake New York, v. 86, n. 1, p. 29-32, 1997.

SOTOMAYOR, A.M.S.B. Avaliação de desempenho e compromisso organizacional: a perspectiva da justiça organizacional. Revista Universo Contábil, v. 3, n. 3, p. 87-100, 2007. 
SPESSATTO, G.; BEUREN, I.M. Análise das diferenças na implantação do Balanced Scorecard nas maiores empresas da região sul do Brasil. Revista Cesumar Ciências Humanas e Sociais Aplicadas, v. 18, n. 2, p. 433-465, 2013.

SPRINKLE, G.B. Perspectives on experimental research in managerial accounting. Accounting, Organizations and Society, v. 28, n. 2, p. 287-318, 2003.

THIBAUT, J.; WALKER, L. Procedural justice: a psychological analysis. Hillsdale, NJ: Earlbaum, 1975.

WIERSMA, E. For which purposes do managers use the Balanced Scorecards? An empirical study. Management Accounting Research, v. 20, n. 4, p. 239-251, 2009. 